\title{
COMPOSIÇÃO CENTESIMAL E TEOR DE COLESTEROL NA CARNE DE EQÜINOS (Equus caballus, Linneaus, 1758) MACHOS E FÊMEAS AGRUPADOS POR PESO DE CARCAÇA ${ }^{1}$
}

\author{
Proximate composition and content of cholesterol in the meat of female and male equines \\ (Equus cabalus, Linneaus 1758) with diferent carcasse weights
}

\author{
Antonio Carlos Andrade Junqueira², Maria Cristina Bressan ${ }^{3}$, Flávia de Floriani Pozza Rebello², \\ Peter Bitencourt Faria ${ }^{4}$, Josye Oliveira e Vieira ${ }^{4}$, Taciana Vilela Savian ${ }^{5}$
}

\begin{abstract}
RESUMO
O presente estudo foi conduzido em frigorífico comercial e as análises no Setor de Tecnologia de Carnes do Departamento de Ciências dos Alimentos da Universidade Federal de Lavras (UFLA). Com o objetivo de avaliar o efeito do sexo e categoria de peso sobre a composição centesimal e teor de colesterol, 20 eqüinos (10 machos castrados e 10 fêmeas) foram abatidos e agrupados em categorias de peso ao abate preestabelecidas, sendo: $C_{1}\left(88,82\right.$ a 97,88 kg); $C_{2}(102,20$ a $115,80 \mathrm{~kg}) ; C_{3}(129,71$ a $160,69 \mathrm{~kg}) ; \mathrm{C}_{4}(162,80$ a 236,40 kg); com 5 animais por categoria. Os músculos longissimus dorsi (LD) e semimembranosus (SM), após o abate, foram coletados e analisados: umidade, gordura, proteína e cinzas (AOAC, 1990) e o colesterol foi determinado por colorimetria (BRAGAGNOLO, 1997). O modelo estatístico foi inteiramente casualizado, em esquema fatorial 2X4, e os dados foram analisadas pelo programa estatístico SAS. O fator sexo influenciou $(\mathrm{p}<0,05)$ os teores de colesterol no músculo LD. As médias encontradas (em base de matéria seca natural) foram de 36,77\% e 56,08\% para macho e fêmea, respectivamente. Os fatores categoria de peso e sexo não influenciaram os valores de umidade, proteína, cinza e gordura, nos músculos LD e SM, cujas médias foram: cinzas 0,70\% e 1,16\%; umidade 75,53\% e 75,83\%; gordura 0,67\% e 2,03\%; proteína 21,63\% e 22,49\% , para os músculos LD e SM, respectivamente. As proporções desses constituintes químicos mostram que a carne de eqüinos obtida em abatedouro comercial apresenta alta quantidade de proteína e baixa de gordura e pode ser considerada uma carne magra.
\end{abstract}

Termos para indexação: Composição centesimal; Carne; Eqüino.

\begin{abstract}
The present study was conducted in a packing house, with the assays being done in the Sector of Meat Technology/Food Science Department of the Universidade Federal de Lavras (UFLA). With the objective of evaluating the effect of sex and category of weight on the meat proximate composition and content of cholesterol, 20 equines (10 castrated males and 10 females) were slaughtered and grouped in pre-established categories of weight: $\mathrm{C}_{1}$ (88.82 to $97.88 \mathrm{~kg}$ ); $\mathrm{C}_{2}$ (102.20 to $115.80 \mathrm{~kg}$ ), $\mathrm{C}_{3}(129.7$ to $160.69 \mathrm{~kg})$ and $\mathrm{C}_{4}(162.80$ to $236.40 \mathrm{~kg})$; with 5 animals for each category. The muscles longissimus dorsi (LD) and semimembranosus (SM) were collected and analyzed for: moisture, fat, protein and ashes (AOAC, 1990) and the cholesterol was determined by colorimetry (BRAGAGNOLO, 1997). The statistical model was completely randomized, in factorial scheme $2 X 4$, and the data were analyzed through the statistical program SAS. The factor sex influenced $(\mathrm{p}<0,05)$ the contents of cholesterol in LD muscle, with average values (in base of dry natural material) of $36.77 \%$ and $56.08 \%$, for males and females, respectively. The factors category of weight and sex had no influence in the values of moisture, protein, ash and fat in the muscles LD and SM, the averages seing: ashes (0.70\% and $1.66 \%)$; moisture (75.53\% and $75.83 \%)$; fat $(0.67 \%$ and $2.03 \%)$; protein $(21.63 \%$ and $22.49 \%$ ) for the muscles LD and SM, respectively. The rates of these chemical components show that, the meat of equines obtained in a packing house presents a high quantity of protein and low quantity of fat and can be considered as a light meat.
\end{abstract}

Index terms: Proximate composition; Meat; Equines.

(Recebido para publicação em 28 julho de 2003 e aprovado em 27 de setembro de 2004)

\section{INTRODUÇÃO}

No Brasil, segundo dados da FAO (2000), foram abatidos aproximadamente 93.500 eqüinos e muares, correspondendo a 132 mil toneladas de carne no perío- do compreendido de 1990 a 1997. Em Minas Gerais, as exportações dessa carne atingiram cifras anuais de 5 mil toneladas anuais em 2001 e 2002, segundo dados oficiais para animais abatidos sob inspeção federal destinados à comunidade européia (FEDERAÇÃO..., 2003).

1. Parte da Dissertação do primeiro autor apresentada à Universidade Federal de Lavras como parte da exigência para obtenção do título de Mestre.

2. Mestre em Ciência dos Alimentos, Universidade Federal de Lavras/UFLA - Caixa Postal 3037 - 37.200-000 - Lavras, MG.

3. Professora do Departamento de Ciência dos Alimentos/DCA/UFLA.

4. Alunos de mestrado em Ciências dos Alimentos/DCA/UFLA.

5. Aluna de mestrado Departamento de Ciências Exatas/DEX/UFLA. 
Esse tipo de carne tem, tradicionalmente, como fator limitante para o consumo humano o preconceito. Por outro lado, existem dispositivos legais que permitem o abate, preparo e distribuição dessa carne no mercado nacional e os produtos que contenham essa matéria-prima devem relacionar, no rótulo, sua presença. Isso tem estimulado sua utilização na indústria de salsicharia (cerca de $2 / 3$ de toda a carne eqüina produzida tem esse destino). Associado a isso, o custo econômico dos animais para o abate é bem inferior ao de bovino, pois, normalmente, são animais de descarte ou animais velhos. Por outro lado, os dados que caracterizam a qualidade físico-química da carne e nutricional são desconhecidos, dificultando o trabalho de divulgação, comercialização e industrialização.

A falta de padronização morfológica de eqüinos para o abate no Brasil leva à necessidade de criar categorias de peso, pois os animais encaminhados ao abate, no sul de Minas, são de diferentes origens, raças e condição sexual e, conseqüentemente, muito heterogêneos. Com o presente trabalho propõe-se uma divisão em quatro categorias de peso, considerando a análise zootécnica dos eqüinos no momento que antecede ao abate: de altura, sendo animais grandes ( $>1,54$ metros) e pequenos ( $<1,54$ metros); e o aspecto de cobertura muscular, baseada em uma adaptação da tabela de escore de condição corporal elaborada por Henneke et al. (1983), em que eqüino magro é aquele que, visualmente, apresenta baixa cobertura muscular na altura das costelas, evidenciando na garupa a ponta dos ossos do ílio e ísquio; e gordo, aqueles eqüinos que apresentam boa cobertura muscular não evidenciando os respectivos ossos.

Objetivou-se com o trabalho caracterizar a carne de eqüinos machos e fêmeas, abatidos no sul de Minas, composição centesimal e teor de colesterol dos músculos longissimus dorsi (LD) e semimembranosus (SM) de eqüinos, considerados como: pequeno e magro (C1) com peso médio de $88,82 \mathrm{~kg}$ a $97,88 \mathrm{~kg}$; pequeno e gordo (C2) de 102,20 kg a 115,80 kg; grande e magro (C3) de 129,71 kg a 160,69 kg e grande e gordo (C4) de $162,80 \mathrm{~kg}$ a $236,40 \mathrm{~kg}$.

\section{MATERIAL E MÉTODOS}

No total, 20 eqüinos (10 machos castrados e 10 fêmeas), sem raça definida, foram abatidos convencionalmente, em um frigorífico do sul de Minas Gerais, no período entre setembro e outubro de 2002.

Os eqüinos no pré-abate foram submetidos a jejum e dieta hídrica regulamentares nos anexos do frigorífico. Os eqüinos, 20 a 30 segundos após o atordoa- mento, foram sangrados, esfolados, eviscerados e divididos em duas meias carcaças. O período entre a insensibilização e a entrada da carcaça na câmara fria foi de 60 minutos. A temperatura inicial das carcaças no interior das massas musculares foi de $27^{\circ} \mathrm{C}$ nos músculos LD e SM. As condições da câmara fria no resfriamento das carcaças foram: temperatura inicial $10^{\circ} \mathrm{C}$, umidade relativa de $86 \%$ e velocidade do ar de $0,12 \mathrm{~m} / \mathrm{s}$. As temperaturas médias das massas musculares das meias carcaças esquerdas, após 24 horas post mortem, foram de 2 e $4^{\circ} \mathrm{C}$ nos músculos LD e SM, respectivamente.

Os eqüinos, após cumprirem o tempo de descanso, foram classificados em quatro categorias de acordo com a altura e o grau de acabamento, numa adaptação da tabela de escore de condição corporal elaborada por Henneke et al. (1983). As categorias foram: categoria 1, animais pequenos $(<1,54$ metros) com baixa cobertura muscular, e pesos post mortem, livre das vísceras, de 88,82 a $97,88 \mathrm{~kg}$ (intervalo de confiança de 93,2 \pm 4,68 $\mathrm{kg})$; categoria 2 , animais pequenos $(<1,54$ metros) com boa cobertura muscular e pesos post mortem, livre das vísceras, de 102,20 a 115,80 kg (intervalo de confiança de $109 \pm 6,80 \mathrm{~kg})$; categoria 3, animais grandes (>1,54 metros) com baixa cobertura muscular e pesos post mortem, livre das vísceras, de 129,71 a 160,69 kg (intervalo de confiança de 145,2 $\pm 15,49 \mathrm{~kg}$ ); categoria 4 , animais grandes ( $>1,54$ metros) com boa cobertura muscular e pesos post mortem, livre das vísceras, de 162,80 a 236,40 kg (intervalo de confiança de 162,80 \pm $36,80 \mathrm{~kg})$.

A distribuição de animais machos castrados e fêmeas foi realizada às 24 horas post mortem em que cada grupo foi formado por cinco animais (cada animal foi considerado uma unidade experimental). Com relação à condição sexual: o grupo $\mathrm{C}_{1}$ foi constituído de 1 macho (M) e 4 fêmeas (F); o $C_{2}$, com 2 M e $3 \mathrm{~F}$; o $\mathrm{C}_{3}$,

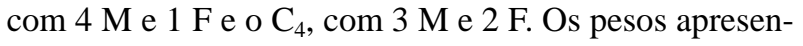
tados pelas carcaças, nas diferentes categorias, foram: $\mathrm{C}_{1}$ (89, 90, 93, 97 e $\left.97 \mathrm{~kg}\right) ; \mathrm{C}_{2}(103,105,109,111$ e $117 \mathrm{~kg}) ; \mathrm{C}_{3}(125,146,146,150$ e $159 \mathrm{~kg}) ; \mathrm{C}_{4}(168,174$, $196,230$ e $230 \mathrm{~kg})$.

As carcaças, 24 horas post mortem, foram desossadas em salas a $12{ }^{\circ} \mathrm{C}$ e os músculos LD e SM foram separados das meias carcaças esquerdas, embalados em papel alumínio e acondicionados em caixa isotérmica a $10^{\circ} \mathrm{C}$ para o transporte até o laboratório. Os músculos, no laboratório, foram congelados a $-12{ }^{\circ} \mathrm{C}$ em freezer convencional e mantidos até a realização das análises.

A determinação da composição centesimal foi realizada com amostras homogeneizadas em multiprocessador até a obtenção de uma massa homogênea. 
A proteína bruta foi quantificada pelo método de análise de nitrogênio Kjeldahl. Os lipídeos totais foram determinados pelo método de Soxhlet, a umidade em estufa a $105{ }^{\circ} \mathrm{C}$ até obtenção de peso constante e as cinzas em mufla a $550{ }^{\circ} \mathrm{C}$ (AOAC, 1990). Todas as análises foram realizadas em triplicata.

Na realização das análises de colesterol, os lipídeos foram extraídos com clorofórmio/metanol (2:1) (FOLCH et al., 1957). O teor de colesterol foi determinado colorimetricamente (BOHAC et al., 1988, adaptado por BRAGAGNOLO \& RODRIGUEZ-AMAYA, 1995).

Para as análises de composição centesimal e teor de colesterol, foi utilizado um delineamento experimental inteiramente casualizado, em esquema fatorial $2 \mathrm{X} 4$, sendo dois sexos (macho castrado e fêmea) e quatro categorias de peso $\left(\mathrm{C}_{1}, \mathrm{C}_{2}, \mathrm{C}_{3}, \mathrm{C}_{4}\right)$. Os resultados foram analisados pelo programa estatístico SAS versão 6.12 (SAS INSTITUTE, 1985). Quando a análise de variância identificou diferenças, os dados foram submetidos ao teste de $\mathrm{T}$.

O modelo experimental para as análises de composição centesimal e teor de colesterol foi:

Yijk $=\mu+\mathrm{Si}+\mathrm{Cj}+$ Eijk, em que:

Yijk = observações no músculo de eqüinos, do sexo i, categoria j em repetições k;

$\mu=$ média geral do experimento;

$\mathrm{Si}=$ efeito do sexo, sendo $\mathrm{i}=1,2$;

$\mathrm{C} \mathrm{j}=$ efeito da categoria de peso, sendo $\mathrm{j}=1,2,3,4$;

Eijk = erro associado à observação

Yijk, normalmente distribuída, com média 0 e variância $\sigma^{2}$.

\section{RESULTADOS E DISCUSSÃO}

As médias de umidade, lipídeos totais, proteína, cinzas e teor de colesterol nos músculos longissimus dorsi (LD) e semimembranosus (SM) e o respectivo erro padrão (EP) estão apresentadas na Tabela 1.

TABELA 1 - Valores médios de composição centesimal dos músculos LD e SM de eqüinos.

\begin{tabular}{|c|c|c|c|c|c|}
\hline \multirow{3}{*}{ Categ/Sexo } & \multicolumn{5}{|c|}{ Variáveis } \\
\hline & Umidade & Proteína & Cinzas & Gordura & Colesterol \\
\hline & \multicolumn{5}{|c|}{ longissimus dorsi } \\
\hline $\mathrm{C}_{1}$ & $75,96^{\mathrm{a}} \pm 0,74$ & $22,34^{\mathrm{a}} \pm 0,52$ & $0,81^{\mathrm{a}} \pm 0,10$ & $1,02^{\mathrm{a}} \pm 0,49$ & $32,38^{\mathrm{a}} \pm 7,17$ \\
\hline $\mathrm{C}_{2}$ & $75,38^{\mathrm{a}} \pm 0,70$ & $21,84^{\mathrm{a}} \pm 0,50$ & $0,71^{\mathrm{a}} \pm 0,09$ & $1,50^{\mathrm{a}} \pm 0,46$ & $45,30^{\mathrm{a}} \pm 6,82$ \\
\hline $\mathrm{C}_{3}$ & $75,45^{\mathrm{a}} \pm 0,74$ & $22,10^{\mathrm{a}} \pm 0,52$ & $0,88^{\mathrm{a}} \pm 0,10$ & $1,25^{\mathrm{a}} \pm 0,49$ & $51,85^{\mathrm{a}} \pm 7,82$ \\
\hline $\mathrm{C}_{4}$ & $75,32^{\mathrm{a}} \pm 0,70$ & $21,95^{\mathrm{a}} \pm 0,50$ & $0,70^{\mathrm{a}} \pm 0,09$ & $2,03^{\mathrm{a}} \pm 0,46$ & $50,26^{\mathrm{a}} \pm 7,57$ \\
\hline $\mathrm{F}$ & $76,03^{\mathrm{a}} \pm 0,52$ & $21,80^{\mathrm{a}} \pm 0,37$ & $0,77^{\mathrm{a}} \pm 0,07$ & $1,47^{\mathrm{a}} \pm 0,34$ & $56,08^{\mathrm{b}} \pm 5,53$ \\
\hline \multirow[t]{2}{*}{ M } & $75,02^{\mathrm{a}} \pm 0,52$ & $22,31^{\mathrm{a}} \pm 0,37$ & $0,79^{\mathrm{a}} \pm 0,07$ & $1,43^{\mathrm{a}} \pm 0,34$ & $36,77^{\mathrm{a}} \pm 5,85$ \\
\hline & \multicolumn{5}{|c|}{ semimembranosus } \\
\hline $\mathrm{C}_{1}$ & $74,55^{\mathrm{a}} \pm 0,66$ & $22,49^{a} \pm 0,65$ & $1,16^{\mathrm{a}} \pm 0,20$ & $1,55^{\mathrm{a}} \pm 0,31$ & $62,07^{\mathrm{a}} \pm 13,30$ \\
\hline $\mathrm{C}_{2}$ & $75,54^{\mathrm{a}} \pm 0,69$ & $22,11^{\mathrm{a}} \pm 0,68$ & $0,88^{\mathrm{a}} \pm 0,22$ & $1,03^{\mathrm{a}} \pm 0,32$ & $46,13^{a} \pm 9,76$ \\
\hline $\mathrm{C}_{3}$ & $76,46^{\mathrm{a}} \pm 0,66$ & $21,63^{\mathrm{a}} \pm 0,65$ & $0,81^{\mathrm{a}} \pm 0,20$ & $0,88^{\mathrm{a}} \pm 0,31$ & $39,54^{\mathrm{a}} \pm 8,47$ \\
\hline $\mathrm{C}_{4}$ & $76,77^{\mathrm{a}} \pm 0,69$ & $22,03^{\mathrm{a}} \pm 0,68$ & $0,71^{a} \pm 0,22$ & $0,50^{\mathrm{a}} \pm 0,32$ & $38,72^{a} \pm 8,97$ \\
\hline $\mathrm{F}$ & $75,56^{\mathrm{a}} \pm 0,49$ & $22,04^{\mathrm{a}} \pm 0,48$ & $1,06^{\mathrm{a}} \pm 0,15$ & $1,32^{\mathrm{a}} \pm 0,23$ & $51,50^{\mathrm{a}} \pm 6,98$ \\
\hline M & $76,09^{\mathrm{a}} \pm 0,49$ & $22,08^{\mathrm{a}} \pm 0,48$ & $0,73^{\mathrm{a}} \pm 0,15$ & $0,67^{\mathrm{a}} \pm 0,23$ & $41,72^{\mathrm{a}} \pm 7,54$ \\
\hline
\end{tabular}

Médias seguidas de mesma letra , na coluna, são estatisticamente iguais pelo teste t e de Tukey a 5\% de significância. Valores médios de colesterol em base de matéria natural (CMN). 
A análise de variância não revelou diferenças $(p>0,05)$ dos fatores sexo e categorias de peso ao abate sobre os percentuais de umidade, proteína, cinzas e gordura nos músculos LD e SM. Os resultados médios encontrados neste trabalho para umidade variaram de 74,55 a 76,77g/100g. Esses resultados foram semelhantes aos valores encontrados por Dufey (1999) que, analisando carne de eqüinos de diferentes idades e níveis de maturação da carne, observou valores médios de 74,43 g/100g de umidade. Entretanto, Badiani et al. (1997) encontraram valores mais baixos de umidade 71,57g/100g, quando analisaram carcaças de cinco animais entre 5 a 10 anos. Em relação a outras espécies, Bragagnolo \& Rodriguez-Amaya (1995) citaram médias de umidade em suínos de 73g/100g e em contrafilé de bovinos de $68 \mathrm{~g} / 100 \mathrm{~g}$. Em ovinos de diferentes raças e pesos ao abate de 15, 25, 35 e $45 \mathrm{~kg}$, Prado (2000) observou que os teores de umidade foram de $76,9 \%$; $75,9 \% ; 74,9 \%$ e $73,9 \%$ para os animais da raça Bergamácia e 76,0\%; 74,9\%; 73,9\% e 72,9\% para os animais da raça Santa Inês, respectivamente, ou seja, animais mais leves mostraram maior teor de umidade do que animais mais pesados. Resultados semelhantes em ovinos foram citados por Bonagurio (2001) e Souza (2001). Em touros jovens da raça Nelore com idade de 690 e 780 dias e carcaças tipificadas pela Inspeção Federal e classificadas como B (Sistema B R A S I L), Abularach et al. (2004), analisando as características de qualidade da carne, observaram que a média de umidade foi de $75,65 \%$.

Comparando-se os trabalhos de Bonagurio (2001) e Souza (2001), verifica-se que os dados de umidade para ovinos foram obtidos em músculos de animais em crescimento e foram determinados em animais adultos, em fase de abate comercial. Velasco et al. (2000) descreveram que maturidade fisiológica influencia a composição centesimal da carne e que, uma vez atingida essa maturidade, o crescimento muscular diminui proteínas e aumenta a quantidade de lipídios.

Os valores encontrados no presente estudo para proteínas não foram afetados pelas variáveis sexo e categoria de peso. As médias encontradas para proteínas variaram de 21,63 a 22,49 g/100g. Esses resultados foram próximos ao valor encontrado por Dufey (1999), que relatou média de 21,31 g/100g. Badiani et al. (1997) encontraram valores de proteína em torno de 20,03g/100g em eqüinos de 5 a 10 anos de idade. Analisando a carne de eqüinos de forma geral, Catalano et al. (1986) e Vervack et al. (1977) encontraram valores de até 24,32 g/100g de proteína, porém, no músculo LD, o valor foi de 21,2 g/100g, próximo aos resultados do presente trabalho. Em ovinos, Souza (2001) encontrou médias em torno de 20,58 a 21,66 g/100g em músculos LD de ovinos com 15, 25, 35 e $45 \mathrm{~kg}$ de peso vivo.

Sexo e categoria de peso não afetaram os teores de cinzas. Os resultados médios encontrados para cinzas foram de 0,70 a $1,16 \mathrm{~g} / 100 \mathrm{~g}$. Esses valores coincidem com os valores citados por Dufey (1999), em média, de 1,00 a $1,13 \mathrm{~g} / 100 \mathrm{~g}$ e por Badiani et al. (1997) que, analisando carne de eqüinos de 5 a 10 anos, encontraram valores de 0,96 a 1,00 g/100g. Devic \& Stamenkovic (1989), analisando a musculatura da coxa em eqüinos, encontraram valores entre 0,96 a 1,00 g/100g. Em bovinos, Morris et al. (1995), avaliando animais abatidos com 7,5 e 25 meses, encontraram valores de 1,02 e 0,93 , respectivamente. E, em bovinos, perus, ovinos e frangos, são relatados valores de 0,92 a 1,2 g/100g (MONTEIRO et al., 2001; NORKUS et al., 2001; PALEARI et al., 1992). Esses resultados mostram que existe semelhança nos percentuais de cinzas da carne eqüina, quando comparada com animais de açougue.

Os resultados médios encontrados para lipídeos foram de 0,67 a 2,03 g/100g. Dufey (1999) cita valores de 1,07; 2,35 e 4,24 g/100g para eqüinos potros, com 30 meses e animais adultos, respectivamente. Badiani et al. (1997) encontram média de 6,63g/100g em animais de 6 a 10 anos de idade. Comparando esses resultados, observa-se que autores relataram percentuais de 4,24 a 6,63g/100g de lipídeos em eqüinos adultos, valores que são 2 a 3 vezes mais elevados do que os dados observados no presente trabalho. As médias de 0,65 a $1,99 \mathrm{~g} / 100 \mathrm{~g}$ para gordura no músculo LD mostram que a carne de eqüinos abatidos nas categorias comerciais $\mathrm{C}_{1}$, $\mathrm{C}_{2}, \mathrm{C}_{3}$ e $\mathrm{C}_{4}$ pode ser considerada carne magra. Os eqüinos abatidos no Brasil são normalmente animais de descarte e, na maioria dos casos, animais velhos, submetidos a condições de manejo imprópio com relação às pastagens e outros cuidados. Possivelmente, a baixa quantidade de gordura seja resultado do manejo dispensado aos animais, embora Sinclair et al. (1982) também tenham relatado valores de $1,02 \mathrm{~g} / 100 \mathrm{~g}$ de gordura na musculatura da perna de eqüinos.

No presente trabalho, sexo e categoria de peso não apresentaram resultados significativos sobre a gordura, tendo a média ficado em 1,22 g/100g. Entretanto, Souza (2001), em ovinos, observou que o sexo teve influência sobre a quantidade de gordura no músculo $\mathrm{LD}$, tendo as fêmeas apresentado maior quantidade (2,90\%) do que machos (2,23\%). Os autores atribuíram essa diferença ao metabolismo das fêmeas na manutenção das funções reprodutivas. 
Os valores médios citados para algumas espécies domésticas (perus, bovinos, ovinos e frangos) variaram de 3,8 a 6,49 g/100g (MONTEIRO, 2001; NORKUS, 2001; PALEARI et al., 1992). Bragagnolo (1997) citou média de 2,5 g/100g em contrafilé de bovinos de raça nelore e média de $3 \mathrm{~g} / 100 \mathrm{~g}$ em lombo de suínos. Os valores médios citados na literatura para diversas espécies permitem verificar que a carne de eqüino se aproxima, em teores de gordura, da carne de touros da raça Nelore, considerados jovens (idade 690 e os 780 dias) e classificados como B (PARDI, 1971).

Pela análise de variância, revelou-se que houve diferença $(p<0,05)$ nos teores de colesterol para machos e fêmeas no músculo LD. Os valores médios encontrados foram de 56,08 mg/100g e 36,77 mg/100g para fêmea e macho, respectivamente. Segundo Reece (1991), as fêmeas de todas as espécies apresentam aptidão para acumular mais lipídeos que machos e essa aptidão começa com as transformações que ocorrem na puberdade, o que pode ser uma das justificativas para os resultados encontrados no presente trabalho. Outro fator que pode influenciar é peso ao abate. Segundo Prado (2000), que trabalhou com cordeiros, houve diminuição do teor de colesterol no músculo LD, quando aumentou o peso vivo do animal. As médias de peso de machos e fêmeas no presente trabalho demonstraram que machos são mais pesados que fêmeas, o que pode causar uma diminuição dos teores de colesterol encontrados em machos. Segundo Velasco et al. (2000), cordeiros de $10 \mathrm{a}$ $12 \mathrm{~kg}$ da raça Talaveriana apresentaram teores de lipídeos mais elevados em fêmeas, semelhante ao encontrado neste trabalho.

Os teores médios de colesterol encontrados neste trabalho foram de $33,20 \mathrm{mg} / 100 \mathrm{~g}$ a $57,26 \mathrm{mg} / 100 \mathrm{~g}$, com média geral de $46,10 \mathrm{mg} / 100 \mathrm{~g}$. A categoria de peso não influenciou significativamente nos valores de colesterol, porém, comparando-se as médias, nota-se que categorias mais pesadas apresentam maiores médias de colesterol. Velasco et al. (2000), em carne de cordeiros de 10 a $12 \mathrm{~kg}$, da raça Talaveriana, encontraram teores de lipídeos maiores em fêmeas, como os resultados encontrados nesse trabalho.

Em eqüinos, Badiani et al. (1997), trabalhando com animais de 6 a 10 anos, citam valor médio de colesterol 61mg/100g. Dufey (1999), comparando eqüinos de diferentes idades, cita valores de 45,9 mg/100g para potros, $45,40 \mathrm{mg} / 100 \mathrm{~g}$ para animais 30 meses mais velhos e $45,8 \mathrm{mg} / 100 \mathrm{~g}$ para animais adultos. Resultado semelhante foi encontrado por Catalano \& Quarantelli (1979), que citam valor médio para eqüino de 40 mg/100g. Sinclair \& O’Dea (1990) citam valores de colesterol para carne de eqüino, em média, de 60 a $70 \mathrm{mg} / 100 \mathrm{~g}$.

Em comparação com outras espécies, valores mais elevados de colesterol foram relatados por Prado (2000), que encontrou, no músculo LD de ovinos, teores de colesterol variando de 65,23 a 76,90 mg/100g. Bragagnolo e Rodrigues-Amaya (1995) citam valores de $58 \mathrm{mg} / 100 \mathrm{~g}$ em carne de peito de frango, 80 $\mathrm{mg} / 100 \mathrm{~g}$ em carne vermelha de frango e $104 \mathrm{mg} / 100 \mathrm{~g}$ em pele de frango. Bragagnolo e Rodriguez-Amaya (1995) reportaram valores de $49 \mathrm{mg} / 100 \mathrm{~g}$ em lombo suíno e $50 \mathrm{mg} / 100 \mathrm{~g}$ em contrafilé de bovinos. Bragagnolo (1997) cita valores de $40 \mathrm{mg} / 100 \mathrm{~g}$ em animais nelore. Comparando os valores encontrados no presente trabalho com os resultados de literatura, constata-se que, de forma geral, a carne de eqüinos apresenta valores mais baixos de colesterol.

\section{CONCLUSÃO}

Os eqüinos abatidos nas diferentes categorias de peso e sexo não influenciaram os componentes químicos da carne nos músculos longissimus dorsi $e$ semimembranosus.

As fêmeas eqüinas mostram maior quantidade de colesterol em amostras de músculos longissimus dorsi do que os machos eqüinos.

As proporções dos constituintes químicos encontradas na carne eqüina (quantidade elevada de proteína e quantidade reduzida de lipídeos), quando comparadas a dados de literatura, revelam que essa é uma "carne magra”, tendo em vista a composição química de carne de animais de açougue, tais como ovinos, bovinos e suínos.

\section{REFERÊNCIAS BIBLIOGRÁFICAS}

ABULARACH, M. L. S.; ROCHA, C. E.; FELÍCIO, P. E. de. Características de qualidade do contrafilé ( m. l. dorsi ) de touros jovens da raça nelore1. Disponível em: $<$ http://www.fea.unicamp.br/deptos/dta/carnes/files/tour o1.pdf>. Acesso em: 18 ago. 2004.

ASSOCIATION OF OFFICIAL ANALYTICAL CHEMISTS. Official methods of analysis of the Association of Official Analytical Chemists. 15. ed. Arlington, 1990.

BADIANI, A. et al. Nutrient profile of horsemeat. Journal of Food Composition and Analysis, San Diego, v. 10, p. 254-269, 1997. 
BOHAC, C. E. et al. Assesment of methodologies for colorimetric cholesterol assay of meats. Journal of Food Science, Chicago, v. 53, n. 6, p. 1642-1645, Nov./Dec. 1988.

BONAGURIO, S. Qualidade da carne de cordeiros Santa Inês puros e mestiços com Texel abatidos com diferentes pesos. 2001.150 p. Dissertação (Mestrado em Zootecnia) - Universidade Federal de Lavras, Lavras, 2001.

BRAGAGNOLO, N. Fatores que influenciam o nível de colesterol, lipídeos totais e composição de ácidos graxos em camarão e carne. 1997. 123 f. Tese (Doutorado em Ciência de Alimentos) - Universidade Estadual de Campinas, Campinas, 1997.

BRAGAGNOLO, N.; RODRIGUEZ-AMAYA, D. B. Teores de colesterol em carne suína e bovina e efeito do cozimento. Ciência e Tecnologia Alimentar, Campinas, v. 15, n. 1, p. 11-17, jan./jun. 1995.

CATALANO, A. L. et al. Produzione di carne da cavalla di diverse categorie. Obiettivi e Documenti Veterinári, [S.l.], v. 7, n. 12, p. 69-73, 1986.

CATALANO, A. L.; QUARANTELLI, A. Caratteristiche di carcassa e composizione chimico-bromatologica delle carni di puledri da latte. Clinique Veterinari, [S.l.], n. 102, p. 498-506, 1979.

DEVIC, B.; STAMENKOVIC, T. Basics characteristics of the horse meat and the possibilities for its processing. Tehnologija Mesa, [S.l.], v. 30, p. 232-237, 1989.

DUFEY, P. A. Fleischqualitat von pferden unterschiedlichen alters. AgrarForschung, [S.l.], v. 6, n. 3, p. 99-102, 1999.

FEDERAÇÃO da Agricultura do Estado de Minas Gerais. Disponível em: <www.faemg.org.br/agronegocios>. Acesso em: 20 nov. 2003.

FOLCH, J.; LEES, M.; STANLEY, G. H. S. A simple method for the isolation and purification of total lipids from animal tissues. Journal Biologics Chemical, [S.1.], v. 226, p. 497-509, 1957.

HENNEKE, D. R. et al. Relationship between condition score, physical measurement, and body fat percentage in mares. Equine Veterinary Journal, London, n. 15, p. 371-372, 1983.
MONTEIRO, E. M.; RUBENSAM, J.; PIRES, G. Avaliação de parâmetros de qualidade da carcaça e da carne de ovinos. In: CONGRESSO BRASILEIRO DE CIÊNCIA E TECNOLOGIA DE CARNES, 1., 2001, São Pedro, SP. Anais... São Pedro: CTC/ITAL, 2001.

MORRIS, C. A. et al. Meat composition in genetically selected and control cattle from a serial slaughter experiment. Meat Science, Barking, v. 39, n. 3, p. 427435, 1995.

NORKUS, E. A. et al. Avaliação da qualidade física e química da carne de frangos abatidos com diferentes idades. In: CONGRESSO BRASILEIRO DE CIÊNCIA E TECNOLOGIA DE CARNES, 1., 2001. São Pedro, SP. Anais... São Pedro: CTC/ITAL, 2001.

ORGANIZAÇÃO DAS NAÇÕES UNIDAS PARA A AGRICULTURA E ALIMENTAÇÃO. Consumo de carne de equino no mundo. [S.l.], 2000.

PALEARI, M. A. et al. Microbiological and chemical aspects of corned, cooked and vacuum packed horsemeat. Journal Food Science, Chicago, n. 4, p. 205-212, 1992.

PARDI, M. C. Classificação e tipificação de carcaças. In: ENCONTRO DAS ASSOCIAÇÕES DE PECUÁRIA DE CORTE, 1., 1971, São Paulo-SP. Anais... São Paulo: [s.n.], 1971. p. 57-62.

PRADO, O. V. Qualidade da carne de cordeiros Santa Inês e Bergamácia abatidos com diferentes pesos. 2000. 109 p. Dissertação (Mestrado em Zootecnia) - Universidade Federal de Lavras, Lavras, 2000.

REECE, W. O. Physiology of domestic animals. Philadelphia: Lea \& Febiger, 1991. 316 p.

SAS INSTITUTE. SAS user's guide: statistics. 5. ed. Cary, 1985. 956 p.

SINCLAIR, A. J.; O’DEA, K. Fats in human diets through history: is the western diet out of step? In: WOOD, J. D.; FISCHER, A. V. Reducing fat in meat animals. London: Elsevier, 1990. p. 1-47.

SINCLAIR, A. J.; SLATTERY, W. J.; O’DEA, K. The analysis of polyunsaturated fatty acids in meat by capillary gas-liquid chromatography. Journal Science Food Agriculture, London, v. 33, p. 771776, 1982. 
SOUZA, X. R. Efeitos de grupos genético, sexo e peso ao abate na qualidade de carne de cordeiros em crescimento. 2001. 119 p. Dissertação (Mestrado em Ciências dos Alimentos) - Universidade Federal de Lavras, Lavras, 2001.

VELASCO, S. et al. Carcass and meat quality of talaverana breed sucking lambs in relation to gender and slaughter weight. Animal Science, Edinburgh, v. 70, n. 2, p. 253-263, Apr. 2000.

VERVACK, W.; VANBELLE, M.; FOULON, M. La teneur en acides amines de la viande. Revue des Fermentations et des Industries Alimentaires, Bruxelles, v. 32, n. 1, p. 16-20, 1977. 